\title{
Practicing Effective Time Management
}

\section{Samantha Vortherms ${ }^{1}$ and Coyle Neal ${ }^{2}$}

\begin{abstract}
Time management is one of the most important skills graduate students need to succeed and thrive in their training. Yet these skills are the exact type of soft skills not explicitly taught and instead, departments and committees assume graduate students will "figure it out" along the way. A quick google search on time management in graduate school results in hundreds of tips and tricks to boost productivity. Oftentimes, however, students find these difficult to implement and unsustainable. This chapter outlines the problems faced by political science graduate students in time management and emphasizes the importance of time management as a practice. Rather than a simple laundry list of techniques, it focuses on three larger strategies that encompass most time management tricks out there: know your priorities, know yourself, and invest time in yourself. By properly understanding the priorities of your program and your personal goals for your graduate studies, you are best able to focus on the work that must get done to achieve them. Knowing yourself allows you to maximize work efficiency, both a key mechanism and result of successful time management. Finally, investing in yourself, including investing time in your personal life, helps you balance work life demands and centers your own mental and physical health, so they do not become the victims of the forward march of time. Each section discusses these strategies for both pre- and post-candidacy, with an emphasis on the latter. This manuscript
\end{abstract}

\footnotetext{
${ }^{1}$ Assistant Professor, Department of Political Science, University of California, Irvine

${ }^{2}$ Associate Professor, Department of History and Political Science, Southwest Baptist University
} 
is part of Strategies for Navigating Graduate School and Beyond, a forthcoming volume for those interested in pursuing graduate education in political science (Fall 2022 publication).

\section{Introduction}

An important difference between undergraduate and graduate education is the amount of time and effort you put into your work outside of formal, structured classes. As you advance in your program, your time becomes less structured. The more flexible your time becomes, the more you're expected to accomplish, driven by your own motivation and organization. Successfully managing different priorities and developing your research agenda in this context depends on time management. Mastering time management skills is essential for successfully completing graduate training.

While healthy time management skills are important for all students, they are particularly important for students who are not "traditional students," i.e. students who have major work and life commitments outside of graduate school. When balancing work, family care, community responsibilities, etc. on top of your coursework, research, and dissertation writing, the demands on your time grow exponentially in often invisible ways. Graduate school and its culture tend to assume none of these out-of-classroom responsibilities exist, so developing and investing in both yourself and in productive habits becomes especially important.

A quick search on time management will yield dozens of bulleted lists of time management tricks. The problem with focusing on time management hacks is the same problem with any healthy lifestyle advice: it is difficult to form new habits. The key to time management is finding strategies that match your priorities with your work style. Because of this, we center 
this chapter on understanding priorities and understanding yourself in how you work to maximize efficiency in work. We also discuss how investing time in yourself helps create balance in your graduate career. Once you identify your priorities and your work style, you can design habits and systems to help you work smarter and accomplish more in less time.

\section{The Value of Time Management as a Practice}

Time is a limited resource that must be budgeted. At any given point, you will need to be reading published research, writing drafts of papers, collecting data, applying for conferences, organizing a lesson plan, grading papers, and reviewing other people's work. Managing time efficiently is a skill that allows you to balance multiple, competing goals. But like any skill, time management is one that requires practice. Inevitably you will miss a deadline or targeted amount of reading. It is essential to allow yourself to adapt and adjust. Plans and goals must be flexible, and you must be willing to reassess and adjust as you learn about yourself and your work. The keys to effective time management are to know your priorities, know yourself, and invest in yourself.

\section{Know your priorities}

Identifying your academic priorities must come first in establishing good time management habits. This can be challenging given the structure of academia and the changing nature of priorities over your career. But defining your priorities helps you focus your time and efforts in the most productive ways. Below are four categories of priorities to consider.

Advancing in the program towards degree completion. Your first professional priority in organizing your time is advancement in the program. What do you need to advance to candidacy? What are the deadlines? 
Priorities before candidacy. Success in graduate school is dependent on coming up with good ideas and then being able to follow those ideas to fruition. Before candidacy, your emphasis should be on developing your ideas for research. So how do you develop good ideas?

The first place to start is with your readings for your coursework. When you read, focus on comprehension and analysis, both of which should be sharpened by informal conversations with your peers outside of class, formal discussion in class, and direction by your professors. Coursework and additional readings culminate in preparation for comprehensive examinations. There are usually far too many texts to read before exams, but as you take classes and talk with professors and older graduate students, you should prioritize texts based on the centrality of the reading and your own research interests.

Reading is also one primary way to develop and refine your own methodological training. When reading, focus on not only the arguments being made but how the authors make them. Published articles are examples of research design and methods that passed peer review. Want to improve training in causal inference? Critically evaluate each class or exam reading for the research method they use and its effectiveness in identification and convincing you of the causal mechanism. Read a paper that uses a "fuzzy regression discontinuity design" and don't know what that is? Google it for some background information on the method then read their methodology section closely to see how they describe it.

Outside of comprehending and retaining information from your reading, pre-candidacy is the time to develop ideas for your future research. For example, if you decide you want to write your dissertation on political parties, you may have opportunities to write in your Congress class about the role of parties on legislation, in your presidency class about how parties affect nominations, in your political theory class about how parties have leveraged ideas about human 
nature into results at the polls, or in your media class about the relationship between partisan news sources and institutional party leadership.

Priorities after candidacy. If the priority pre-candidacy is the generation of new ideas, the priority after candidacy is following through on those ideas.

Having finished your coursework and passed your comprehensive examinations, the amount of reading might not change, but how you prioritize materials should. Your reading priorities should now focus on three areas: your specific topic of research, how your specific research topic fits into the broader discipline, and general academic trends. Your professors can help guide you to broad areas of research to read, but this is also the time for you to take ownership of your own area of expertise.

The two other priorities after candidacy are completing research and writing. These two areas are likely to grow significantly compared to before candidacy. For example, empirical research involves identifying sources, collecting data, analyzing data, and writing all along the way. You may also need to write grant applications at various points. All of these activities take time, and it is essential to balance your time so that you are making progress.

Graduate students are often tempted to spend too much time collecting data and not enough time analyzing or evaluating it. Other students continually apply for grants to support their research while neglecting the research itself. And this is all in addition to normal graduate production: developing and producing arguments, writing papers for conferences, refining papers for publication, and, of course, writing the dissertation. Balancing these priorities by setting limits on how much time you spend on each task while protecting time to advance towards longterm goals is essential. 
Training for post-Ph.D. employment. While Ph.D. programs are primarily designed to train the next generation of academic researchers, academic research is not the only use of a $\mathrm{PhD}$. As you advance in your program, think about what your career goals are to help define valuable and effective uses of your time. What activities and items on your to-do list most directly help you meet these priorities? For ideas on these types of activities, see Chapters 34-50 relating to different elements of the job market.

\section{Know yourself}

The only way to regulate your time according to your priorities is to fully understand yourself, how you work, and what you need to be productive. We propose the following questions to help you know what you need to be your most productive.

What are your priorities? Building off of the last section, what are the most important professional and personal priorities? Explicitly assign and protect time dedicated to your most important priorities.

What do you need for focus? We all have our preferences when it comes to the work environment. Are you a coffee-shop scribbler? A library regular? What is your "must have" writing kit? Sam's work kit includes headphones (above all else), scrap paper and colorful pens, and a tumbler for tea. Set yourself up to focus on work and only work during work time. How do you best absorb and evaluate information? Pre-candidacy, most of your time and energy is spent on absorbing and analyzing information through reading. Because of its flexibility, you can squeeze reading in almost anywhere: public transit, waiting in line, in bed, while eating, anywhere you've got a free hand you can be holding a book or an e-reader. But be aware of what you need to read well and plan your reading accordingly. If you're the type who can retain and comprehend when reading in snippets, then plan to have a book with you at all 
times and read when you can. If you're the type who needs more time to get into the book, arrange your schedule accordingly.

What time of day is most productive for you? Is the first hour of the day your most productive? Do you feel like your creativity peaks at night? As you work, pay attention to when work "clicks" more and when you find more resistance. Reserve your most productive time for your most important and most cognitively demanding tasks and plan on doing lighter work when you are naturally less productive.

What are your (unproductive) rabbit holes? We all have them, the small tasks that tend to distract us and take more time than we should spend on them. You might be prone to the neverending literature review search; re-reading source material "just one more time;" the siren song of a new project or paper; or, my personal favorite, cleaning data. Spending too much time on one task that does not deserve it is the enemy of efficiency. Knowing yourself will help you take steps to offset this tendency, whether by setting strict limits on how long you allow for these distracting tasks, relegating them to the times when you are already less productive, or by whatever method works best for you.

Are you experiencing writing resistance? Situations where we pull away from what we should really be working on are symptoms of resistance to writing. We resist writing for any number of reasons, from fear of failure (I don't know what I'm doing and this article has no value) to fear of success (what if I can't live up to the hype of this grant award?). Just like rabbit holes, we tend to have repeating patterns, go-to procrastination outlets that waste time (searching for playlists, getting up from our desks for coffee, etc.). Identifying your distractions, your time-wasting resistance strategies is necessary to work past them. 


\section{Invest time in yourself}

Up until this point, this chapter focused on your professional time and the value of thinking of time management as a practice. But non-work time is also critical. Graduate school can be all-encompassing and it is easy for work to seep into every hour of every day. But a 24/7, always-on lifestyle is neither sustainable nor efficient. Graduate school is a marathon, not a sprint. Inherent in the argument that time should be managed is that work time is a discrete part of your day and should be balanced with personal time. Time spent at the gym, developing a hobby, or investing in relationships with family and friends is essential for time management. Investing in yourself when not working prevents burnout - the bane of efficient productivity.

Between work, personal, and financial pressures, having a balanced life as a graduate student can be very difficult. Nevertheless, this balance is crucial. As with your studies, you must think about the quality and efficiency with which you spend your personal time. What are the activities in your personal life that you find particularly fulfilling? What activities can you do in the evening that relieve stress and promote healthy living not only because you need to have a life, but also because a healthy personal life helps you be a more effective scholar? Healthy, balanced lifestyles promote long-term productivity and mental health in an often-challenging professional environment. You are a person first and a graduate student second.

\section{General tips}

Below are some of the most common tips for effective time management broadly.

Get organized. You cannot juggle teaching, research, writing, emails, conferences, grant applications, and anything else along the way unless you have a way of tracking it. There are a plethora of free organizational tools such as Trello, Asana, and Microsoft to-dos, but sometimes 
good old paper planners are the best for your workflow. Invest time in finding a system that works for you.

Make a timeline and target deadlines for yourself. Identify when your big program requirements are due and start to work backwards to make intermediary deadlines for yourself. Imagine you are planning on applying for the APSA Doctoral Dissertation Research Improvement Grant. The deadline is June $15^{\text {th }}$. For the application, you must have your advisor's support. This means they need to see a full version of your proposal well ahead of the deadline, so set a personal deadline of June 1 for the full final proposal. But you don't want to send your advisor an unedited draft of the proposal, so you set a deadline to send your draft to a friend for feedback mid-May. You can continue this process back through the very early steps of any project or deliverable. Intermediate deadlines will help keep you on track.

Make a plan, then revise it, then revise it again. Time management is a practice. Rarely do we make a master plan and follow it all the way through to completion perfectly. At the beginning of each term, sit down and write out your timeline for the term. Then every Monday morning, review your timeline. What did you accomplish last week and what did you not finish? Then adjust your plan. What has to get moved to the next week? Don't let yourself fall into the trap of rolling over projects constantly. Unlike budgeting money, time cannot be earned back. When you find yourself rolling over too many tasks, what can you cut out? Prioritize tasks and take off what is not going to get done, so you can focus more time on what matters most.

Break large tasks into smaller to-dos. Smaller tasks are more actionable and can be completed in less time, allowing you to fill in gaps in your schedule with productivity.

Set aside time every day to read and write. For reading, set a daily reading goal that is reasonable, then increase it slightly but regularly until you can't keep up with it, then back off a 
bit. This can be either page numbers or a time for reading, depending on your availability. For example, start with 25 pages/class/day. Then increase that to 30 pages, then 35 , and so on until you find a maximum amount that you can routinely complete. If 40 pages per class is too much, drop back to 35 or so and hold there daily. The goal is to develop a habit of reading that lets you cover enough material in your available time without sacrificing comprehension. If on a given day you get into a reading and knock out 300 pages, that doesn't count as next week's reading. Pick back up the next day with a new 30 pages. If you miss today, you don't get to make it up by aiming for 60 pages tomorrow. The missed day is gone forever-it's far more important that you build the habit of regular reading than that you hit a specific total number of pages.

Similarly with writing, block off your writing time and protect it. Actually block off writing chunks in your calendar as an appointment with yourself. Turn off as many distractions as possible and go to your writing "happy place." Some people like to set writing goals by word limits (minimum 500 words a day), others work by time (every day from 9am-11am). As with reading, word goals can be gradually increased over time as your graduate career advances. Precandidacy, use writing time to analyze readings and draft term papers. Post-candidacy, work on your dissertation, papers for publications, and writing samples for the job market.

Learn to say no. While department events and activities in the discipline are essential for socialization, networking, and professionalization, you do not have to do everything. If you're asked to take part in events or organize groups of students, be strategic. How will the event help your personal and professional development? Be proactive but do not over-extend yourself. Learning to say no is particularly important for students from underrepresented backgrounds as you may receive more requests for participation on panels and campus discussions. We encourage you to prioritize a balance between what you want and what you need. Which of these 
activities do you find particularly fulfilling or provide you with additional support and which activities don't? Pick and choose what works for you while protecting the time needed to advance through your program.

Know yourself and your priorities. A good practice is to track your time. How much time do you spend on any given task? Within one week, how much time do you spend on reading and how much on writing? How much time did you spend on teaching? Looking at that distribution, does it match the priorities of your program and your current stage? Are you dedicating enough time to the tasks that are worth your attention?

Finally, it is important to understand your own limits. Time is a valuable resource that you should budget and track like money. Very few graduate programs provide an infinite amount of time to complete programs, and everyone's successful to-do list is limited by both time and energy. Setting your goals too high can backfire, creating stress and anxiety that reduce your productivity and can lead to burnout. You won't be able to do it all, so it is important to learn to prioritize what matters. Then, by knowing yourself, you can work efficiently and effectively to reach your goals in a healthy and balanced way. 